\title{
Energy Consumption Forecasting based on Hybrid Neural Fuzzy Inference System
} \author{
IPP - Polytechnic of Porto, \\ Porto, Portugal \\ $\{$ arjoz, tmcfp, icp, fspsa, bccta, zav $\} @$ isep.ipp.pt
}

Aria Jozi, Tiago Pinto, Isabel Praça, Francisco Silva, Brigida Teixeira, Zita Vale

GECAD - Research Group on Intelligent Engineering and Computing for Advanced Innovation and Development,

\begin{abstract}
Forecasting the electricity consumption is one of the most challenging tasks for energy domain stakeholders. Having reliable electricity consumption forecasts can help minimizing the cost of electricity and also enable a better control on the electricity tariff. This paper presents a study regarding the forecast of electricity consumption using a methodology based on Hybrid neural Fuzzy Inference System (HyFIS). The proposed approach considers two distinct strategies, namely one strategy using only the electricity consumption as the input of the method, and the second strategy uses a combination of the electricity consumption and the environmental temperature as the input. A case study considering the forecasting of the consumption of an office building using the proposed methodologies is also presented. Results show that the second strategy is able to achieve better results, hence concluding that HyFIS is an appropriate approach to incorporate different sources of information. In this way, the environmental temperature can help the HyFIS method to achieve a more reliable forecast of the electricity consumption.
\end{abstract}

Index Terms - Electricity Consumption, Environmental Temperature, Forecasting, Hybrid Neural Fuzzy Inference Systems

\section{INTRODUCTION}

Environmental concerns about the impact of electricity led to new energy policies envisaging the increased use of renewable energy sources. The European Union (EU) has assumed a pioneer and leading role in this field and has committed to reach ambitious targets [1]. As a consequence, huge investments have been made, e.g. in smart meters [2]. However, the smart metering by itself does not ensure that the potential consumers' active participation is used in an effective and interesting way. Although many documents refer the consumers' active participation as a crucial aspect, the opportunities brought by the smart metering availability are not being explored and there is not enough research in the field.

The present work has been developed under the EUREKA - ITEA2 Project FUSE-IT (ITEA-13023), Project GREEDI (ANI|P2020 17822), and has received funding from FEDER Funds through COMPETE program and from National Funds through FCT under the project UID/EEA/00760/2013.
In order to take advantage of the full potential of flexibility from consumers, effective consumption forecasting methodologies are crucial. Reliable consumption forecasts are also essential to enable electricity operators to have a better control on the power distribution network [3], e.g. by supporting the management of reserved electricity to be used in emergency scenarios. In this way, the generation cost for electricity can be minimized, and dynamic electricity tariffs that bring the most advantages out of consumers' participation can be defined [4].

Several studies can be found in the literature, related to energy consumption forecasting. In [3], the author proposes the use of support vector machines to analyze the statistical data that influences electricity consumption. This is achieved by discovering the intrinsic rules, and putting forward the corresponding electricity consumption forecasting model. The forecast of electricity consumption is performed with the actual data from 1980 to 2004, and results suggest that this is an accurate method to predict the electricity consumption. The forecast of electricity consumption in Malaysia is presented in [4], based on Artificial Natural Networks (ANN). The work presented in [5] demonstrates the forecast of electricity consumption by separating the periodic variable and decompositions the pattern. By changing a set of simple patterns that can easily be used in the point of view of macro decision making, the parameters that affect the consumption patterns are determined. Results are hence improved using descriptive estimation for any part of consumption pattern in any time interval. In [6] the author applies an ANN in order to forecast the consumption of an office building. Most of these works achieve acceptable results. However, the integration of correlated external variables, which can aid the forecast of energy consumption, such as the influence of temperature, brightness, among others, is still insufficiently studied.

This paper proposes the use of an Hybrid neural Fuzzy Inference System (HyFIS) to forecast energy consumption [7]. Two different strategies based on HyFIS are presented and compared. These approaches differ by using a combination of the electricity consumption and environmental factors as inputs for training the method. In specific, the environmental temperature has been used, as a variable that has a direct influence on electricity consumption. 


\section{MATERIAL AND METHODS}

This paper studies the electricity consumption forecasting based-on hybrid neural fuzzy inference system (HyFIS). Real consumption data measured from the campus buildings of the Research Group on Intelligent Engineering and Computing for Advanced Innovation and Development (GECAD) research center located in ISEP/IPP, Porto, Portugal is used. Environmental data from the same site is also used, in specific the environmental temperature [8]. The electricity consumption forecast is calculated based on two strategies:

- HyFIS1: This strategy uses only the log of historic electricity consumption as input;

- HyFIS2: This strategy considers a combination of the electricity consumption and the environmental temperature as inputs.

The implementation details of these two strategies are discussed in the following sections. The achieved results are compared and assessed in section III.

a) Hybrid neural Fuzzy Inference System (HyFIS)

The learning method in HyFIS includes two phases, which are described as follows [9]:

- The first phase concerns the structure learning, i.e. finding the rules by using the knowledge acquisition module;

- The second phase regards the parameter learning phase for tuning fuzzy membership functions [10] to achieve a desired level of performance.

One of the advantages of this approach is that the fuzzy rule base can be easily updated when there is new available data [11]. When there is a new available pair data, a rule is created for this data and the fuzzy rule base is updated by this new rule, as shown in Fig.1.

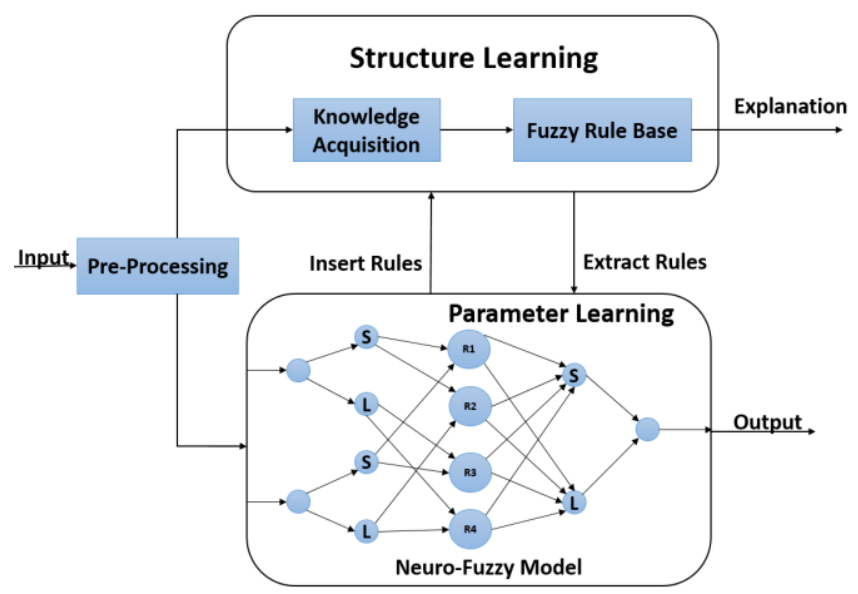

Fig.1: General schematic diagram of the HyFIS.

In the learning phase, the neuro-fuzzy model in the HyFIS uses a multilayered perceptron (MLP) network based on a gradient descent learning algorithm for adapting the parameters of the fuzzy model [12]. The architecture simplifies learning from data and approximate reasoning, as well as knowledge acquisition. It allows using the combination of both numerical data and fuzzy rules thus producing the synergistic benefits associated with the two sources.

The proposed neuro-fuzzy model in the HyFIS is a multilayer ANN, based on a combination with fuzzy systems. The system includes five layers, as shown in Fig.2. In this structure, the input and output nodes are the input state and output control/decision signals respectively. The nodes in the hidden layers detain the responsibility of representing the membership functions and rules.

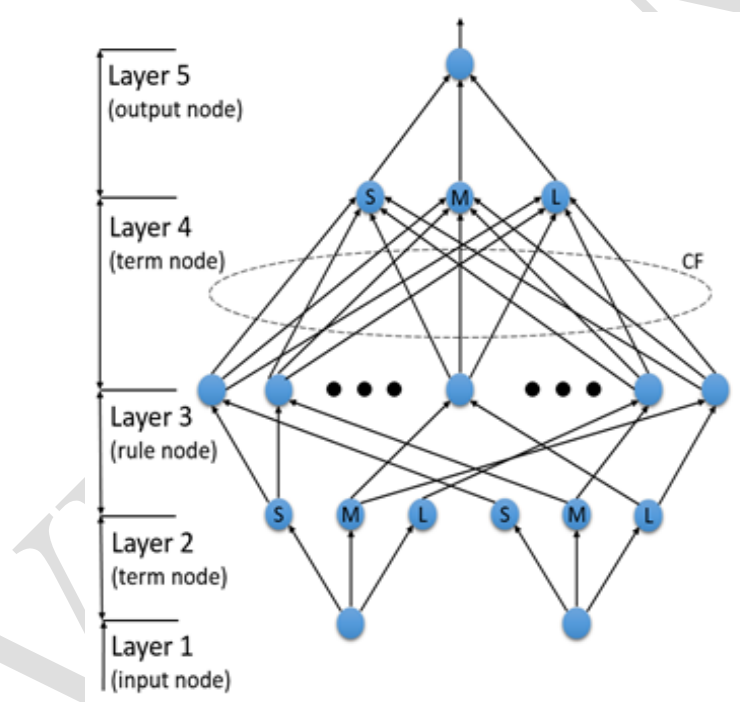

Fig.2 - The structure of the Neuro-Fuzzy model from the HyFIS architecture.

In the first layer, the nodes are the inputs that transmit input signals to the next layer. In the second and fourth layers, nodes are the term nodes. These nodes act as membership functions to express the input-output fuzzy linguistic variables. In this layers, the fuzzy sets defined for the input-output variables are represented as: large (L), medium (M), and small (S). However, for some applications or specific cases, these can be more specific and represented as, e.g. large positive (LP), small positive (SP), zero (ZE), small negative (SN), and large negative $(\mathrm{LN})$. In the third layer, each node is a rule node and represents one fuzzy rule. The connection weights between the third and fourth layer represent certainty factors of the associated rules, i.e. each rule is activated to a certain degree controlled by the weight values. Finally, the fifth layer detains the node that represents the output of the system.

\section{b) Data base description}

In this approach, the SQL server of GECAD research center located in ISEP/IPP, Porto, Portugal has been used. This server has the database with all electricity information of GECAD campus buildings. In this work, building $\mathrm{N}$ of ISEP/GECAD is used. This building has five energy meters, and each of them stores the electricity consumption data of one specific part of the building with 10 seconds time interval. There is another SQL server database, which contains the complete weather information obtained from ISEP meteorology website [8]. The environmental temperature of the related place with 10 seconds time interval has been chosen from this database. 
In this implementation, a Java based application has been developed to receive the information from the SQL server database, and calculate the average of environmental temperature as well as the total electricity consumption of the building $\mathrm{N}$ - ISEP/GECAD per each hour. The proposed HyFIS approach has been developed based on $\mathrm{R}$ programming language.

\section{RESULTS AND DISCUSSION}

The objective of this research is to forecast the electricity consumption for the following hour. The proposed HyFIS method has been employed for this forecast, using the two different strategies to compare the achieved results. The HyFIS1 strategy uses as input for the HyFIS method only the electricity consumption from every hour since the beginning of the day until one hour before the hour of the forecast. The HyFIS2 strategy uses as input for the HyFIS method, a combination of the electricity consumption and the environmental temperature of the related place from every hour since the beginning of the day until one hour before the hour of the forecast. The objective of HyFIS2 is to use a combination of variables that affect the forecasted variable, in order to study the possibility of improving forecasting results by extracting correlations between the different variables. The environmental temperature, as one of the main variables that influences the energy consumption, is therefore used as forecast input.

\section{a) HyFIS1 strategy}

The Java application, which is connected to the GECAD SQL server database, is used to extract the electricity consumption for each energy meters from the database. Once collected, the total electricity consumption of the building is calculated, as well as the average consumption values for each hour.

For each forecast, a set of the 14 days prior to the target forecasting date has been used as the training input of the HyFIS method. Once the HyFIS is trained, the input values for the actual forecast consider the consumption values since the beginning of the day until one hour before the hour of the forecast. An excerpt of the used data is shown in Table.1, for the case of forecasting hour 4 of the day: 10/11/2015.

Table.1 - Excerpt of HyFIS1 test input table for hour 4 of 10/11/2015

\begin{tabular}{|c|c|c|c|c|}
\hline Hour & 0 & 1 & 2 & 3 \\
\hline $\begin{array}{c}\text { Consumption } \\
(\mathbf{W})\end{array}$ & 1168.68 & 1232.70 & 1229.05 & 1715.24 \\
\hline
\end{tabular}

For testing the HyFIS1 approach, a total of 12 hours have been forecasted, namely from 12:00 until 23:00 of 10/11/2015. These hours have been chosen because they refer to the hours of greatest activity in the building (higher variation in consumption), thus being the most interesting hours to forecast. For each hour there an excel file has been created by the Java application, which contains 3 tables: (i) Training input, (ii) Training output, and (iii) Testing input. The resulting forecasted values are compared to the real values of each hour using the MAPE (Mean Absolute Percent Error) error calculation formula. Table 2 shows a comparison between the forecasted values and the real values for each of the 12 hours, including the MAPE error value for each of these hours.
Table. 2 - HyFIS1 results for the 12 considered hours of 10/11/2015

\begin{tabular}{|c|c|c|c|}
\hline Hour & $\begin{array}{c}\text { Real } \\
\text { Consumption } \\
(\mathbf{W})\end{array}$ & $\begin{array}{c}\text { HyFIS1 } \\
\text { Forecasted } \\
\text { Consumption } \\
(\mathbf{W})\end{array}$ & $\begin{array}{c}\text { MAPE } \\
\text { Forecasting } \\
\text { Error (\%) }\end{array}$ \\
\hline 12 & 3135.3 & 2821.982 & $10 \%$ \\
\hline 13 & 4103.719 & 3329.097 & $18.87 \%$ \\
\hline 14 & 3117.517 & 3132.097 & $0.19 \%$ \\
\hline 15 & 3589.989 & 3575.397 & $0.40 \%$ \\
\hline 16 & 3308.593 & 2778.585 & $16.01 \%$ \\
\hline 17 & 3802.058 & 2722.728 & $28.39 \%$ \\
\hline 18 & 3102.905 & 1652.059 & $47.79 \%$ \\
\hline 19 & 2078.291 & 2002.997 & $3.62 \%$ \\
\hline 20 & 1323.013 & 1419.3 & $7.28 \%$ \\
\hline 21 & 1303.217 & 1266.318 & $2.83 \%$ \\
\hline 22 & 1313.895 & 1204.553 & $8.32 \%$ \\
\hline 23 & 1280.756 & 1212.832 & $5.30 \%$ \\
\hline
\end{tabular}

From Table 2 it is visible that a certain degree of variation in the quality of results is verified. The average of forecast errors for the HyFIS1 approach is $12.42 \%$.

\section{b) HyFIS2 strategy}

The HyFIS2 strategy uses as input a combination of the electricity consumption and a variable that can affect the electricity consumption. In this specific research work, the environmental temperature has been used as the second variable. In this strategy the electricity consumption is received and calculated as the same way as the HyFIS1, and the environmental temperature is extracted from ISEP meteorology website [8] for each 10 seconds. The Java application calculates the average environmental temperature for each hour of the days considered for training and testing the HyFIS2 strategy. The inputs of HyFIS2, thereby consider two values for each hour: the electricity consumption and the environmental temperature. Table. 3 shows an excerpt of the input test data of the HyFIS2 strategy, for the case of forecasting the consumption in hour 2 of day 10/11/2015.

Table. 3 - Excerpt of HyFIS2 test input table for hour 2 of 10/11/2015

\begin{tabular}{|c|c|c|}
\hline Hour & 0 & 1 \\
\hline Temperature $\left({ }^{\mathbf{0}} \mathbf{C}\right)$ & 15.09 & 14.8 \\
\hline Consumption $(\mathbf{W})$ & 1168.68 & 1232.70 \\
\hline
\end{tabular}

The training input of the HyFIS2 strategy, similarly to HyFIS1, considers data from the 14 days prior to the date of the forecast. The training output table for HyFIS2 contains only the electricity consumption of the same hour of the forecast hour from 14 days before the forecast date.

With the purpose of testing the HyFIS2 strategy, the same hours as the HyFIS1 have been used, namely 12 hours of 10 November 2015, from 12:00 until 23:00. Table 4 shows a comparison between the forecasted values and the real values for each of the 12 hours, including the MAPE error value for each hour. 
Table.4 - HyFIS2 results for the 12 considered hours of 10/11/2015

\begin{tabular}{|c|c|c|c|}
\hline Hour & $\begin{array}{c}\text { Real } \\
\text { Consumption } \\
(\mathbf{W})\end{array}$ & $\begin{array}{c}\text { HyFIS2 } \\
\text { Forecasted } \\
\text { Consumption } \\
(\mathbf{W})\end{array}$ & $\begin{array}{c}\text { MAPE } \\
\text { Forecasting } \\
\text { Error (\%) }\end{array}$ \\
\hline 12 & 3135.3 & 3282.7446 & $4.70 \%$ \\
\hline 13 & 4103.719 & 3329.0974 & $18.87 \%$ \\
\hline 14 & 3117.517 & 3123.5137 & $0.19 \%$ \\
\hline 15 & 3589.989 & 4000.3934 & $11.43 \%$ \\
\hline 16 & 3308.593 & 3442.8786 & $4.06 \%$ \\
\hline 17 & 3802.058 & 3692.3482 & $2.88 \%$ \\
\hline 18 & 3102.905 & 2588.4948 & $16.58 \%$ \\
\hline 19 & 2078.291 & 2002.9969 & $3.62 \%$ \\
\hline 20 & 1323.013 & 1419.2475 & $7.27 \%$ \\
\hline 21 & 1303.217 & 1266.3181 & $2.83 \%$ \\
\hline 22 & 1313.895 & 1204.6165 & $8.32 \%$ \\
\hline 23 & 1280.756 & 1212.665 & $5.32 \%$ \\
\hline
\end{tabular}

From Table 4 it is visible that the variation of the forecasting error values is much smaller than that verified by using the HyFIS1 approach. The average of the MAPE errors achieved by the HyFIS2 is $7.17 \%$.

\section{c) Comparison of results}

By comparing the results of both strategies for the same date and same hours shows that when the environmental temperature is used in the input of the method the result has a smaller error. The average MAPE forecasting error for the considered 12 hours of 10/11/2015 when using the HyFIS1 is $12.42 \%$, while when using the HyFIS2 the average error is $7.17 \%$. This difference in forecasting error can be visualized by Fig.3, which shows that for most of the hours, the results achieved by the HyFIS2 strategy are much closer to the real values than the results of the HyFIS1 approach.

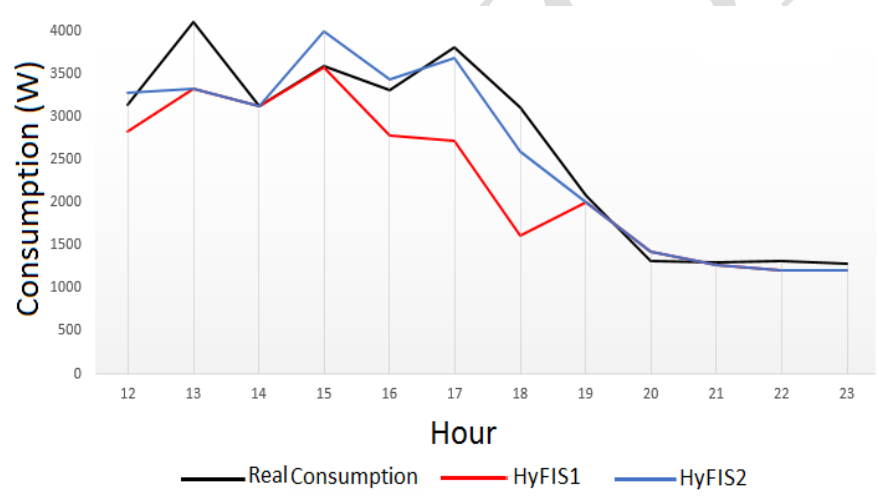

Fig.3 - Compare the results of the strategies.

As the Fig. 3 demonstrates, during the hours of more activity in the building (during hours 12:00 to 18:00), some appliances, for instance the air conditioning system, can be widely used comparing with other moments. Such appliances present a large consumption, and is directly influenced by the temperature (input value used by HyFIS2). This results in HyFIS2 achieving lower forecasting errors during most hours, as shown by Fig.4.

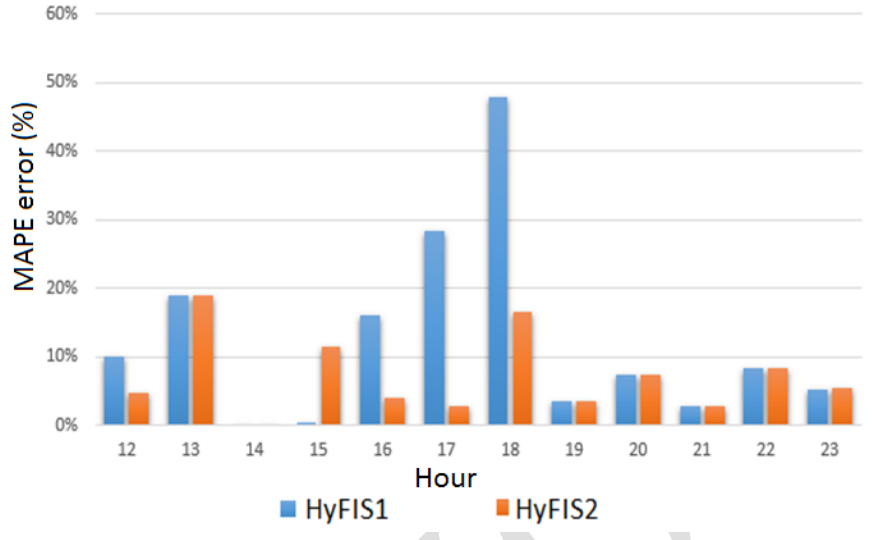

Fig.4 - Forecasting errors of both strategies during the considered hours

As can be seen by Fig. 4, during the hours or larger activity in the building, the error is highly variable, and HyFIS2 is able to achieve much better results than HyFIS1. In fact, the proposed HyFIS2 approach is also able to achieve better results than other previously experimented forecasting approaches. The study presented in [6] has dealt with the electricity consumption forecast problem using a set of different ANN based approaches, which are summarized in Table.5.

Table.5-Different ANN neurons input / output definition, from [6]

\begin{tabular}{|c|c|c|c|c|}
\hline \multirow{2}{*}{$\begin{array}{c}\text { Id } \\
\text { ANN }\end{array}$} & \multicolumn{2}{|c|}{ Input neurons } & \multicolumn{2}{|c|}{ Output neurons } \\
\hline & No. & Description & No. & Description \\
\hline $\mathrm{ANN}_{-} 1$ & 3 & $\begin{array}{l}\text { - Context } \\
\text { data }^{*}\end{array}$ & 1 & $\begin{array}{c}\text { - Total } \\
\text { consumption } \\
\text { per hour }\end{array}$ \\
\hline ANN_2 & 3 & - Context data & 3 & $\begin{array}{l}\text { - Consumption } \\
\text { of HVAC; } \\
\text { - Consumption } \\
\text { of lights; } \\
\text { - Consumption } \\
\text { of sockets }\end{array}$ \\
\hline ANN_h & 4 & $\begin{array}{c}\text { - Context } \\
\text { data; } \\
\text { - External } \\
\text { environmental } \\
\text { data }^{* *} \\
\end{array}$ & 1 & $\begin{array}{c}\text { - Consumption } \\
\text { of HVAC }\end{array}$ \\
\hline ANN_1 & 4 & $\begin{array}{c}\text { - Context } \\
\text { data; } \\
\text { - External } \\
\text { environmental } \\
\text { data } \\
\end{array}$ & 1 & $\begin{array}{c}\text { - Consumption } \\
\text { of light }\end{array}$ \\
\hline ANN_s & 4 & $\begin{array}{c}\text { - Context } \\
\text { data; } \\
\text { - External } \\
\text { environmental } \\
\text { data }\end{array}$ & 1 & $\begin{array}{c}\text { - Consumption } \\
\text { of sockets }\end{array}$ \\
\hline
\end{tabular}

${ }^{*}$ The context data refer to: hour; day of the week and hour of work (the hour of work is characterized as: time of high, medium and low permanency in the building);

${ }_{* *}^{*}$ The external environment data refers to the following variables: temperature, temperature felt, radiation, precipitation and humidity. 
Table.6 shows a comparison between the electricity consumption forecasting error results achieved by the several ANN (from [6]) and the forecasting results achieved by HyFIS1 and HyFIS2 strategies.

Table.6 -Forecasting errors of the ANN and HyFIS methods

\begin{tabular}{|c|c|c|}
\hline Methods & MAPE(\%) & SMAPE(\%) \\
\hline ANN_1 & $16.9 \%$ & $17.1 \%$ \\
\hline ANN_2 & $15.0 \%$ & $15.3 \%$ \\
\hline ANN_h & $10.3 \%$ & $10.8 \%$ \\
\hline ANN_1 & $18.1 \%$ & $19.6 \%$ \\
\hline ANN_s & $12.6 \%$ & $14.2 \%$ \\
\hline HyFIS1 & $12.42 \%$ & $14.41 \%$ \\
\hline HyFIS2 & $7.17 \%$ & $7.42 \%$ \\
\hline
\end{tabular}

As summarized by Table.6, the HyFIS2 strategy is able to achieve better forecasting results than all the other strategies. The HyFIS1 approach is also able to achieve a smaller forecasting error than the most of the ANN strategies.

\section{CONCLUSION}

Given the importance of adequate electricity consumption forecast methodologies that can be able to make reliable predictions of consumption, this paper focuses on studying alternative approaches with the potential of, not only improving the forecasting results of this type of methods, but also doing it by incorporating relevant information from external factors.

This paper has proposed two different strategies (HyFIS1 and HyFIS2) for forecasting the electricity consumption. The HyFIS1 strategy uses the electricity consumption data as the only input of the method. In turn, the HyFIS2 applies the combination of the electricity consumption data and the environmental temperature information. The achieved results, shown in this paper, illustrate that using the environmental temperature data is much effective for the electricity consumption forecasting when using adequate methodologies that are able to suitably incorporate different sources of information by finding correlations between the different types of data. The quality of results of the proposed approach is especially relevant during times when there is more activities in the building. During these moments, several appliances, namely air condition systems, can be used in order to regulate the temperature of the environment. Therefore, the HyFIS method can provide more reliable electricity consumption data by using the environmental temperature information and finding associations between these data and energy consumption values.

As future work, the influence of other external factors, such as brightness and humidity, will also be studied. Associations between several variables simultaneously will also be considered, in order to extract conclusions in their impact on energy consumption forecasting.

\section{REFERENCES}

[1]. European Commission, "2030 framework for climate and energy policies", 2014, Available:

http://ec.europa.eu/clima/policies/2030/index_en.htm [accessed in March 2016]

[2]. European Commission, "Benchmarking smart metering deployment in the EU-27 with a focus on electricity", 2014, Available: http://ses.jrc.ec.europa.eu/smartmetering-deployment-european-union [accessed in March 2016]

[3]. S. X. Yang and Y. Wang, "Applying Support Vector Machine Method to Forecast Electricity Consumption," Computational Intelligence and Security, 2006 International Conference on, Guangzhou, 2006, pp. 929932.

[4]. M. S. M. Othman, D. Johari, I. Musirin, T. K. A. Rahman and N. F. N. Ismail, "Artificial neural networkbased forecast for electricity consumption in Malaysia," Power and Energy (PECon), 2010 IEEE International Conference on, Kuala Lumpur, 2010, pp. 24-28.

[5]. S. F. Ghaderi, A. Azadeh and H. S. Keyno, "Forecasting electricity consumption by separating the periodic variable and decompositions the pattern," Industrial Engineering and Engineering Management, 2007 IEEE International Conference on, Singapore, 2007, pp. 292296.

[6]. E. Vinagre, L. Gomes and Z. Vale, "Electrical Energy Consumption Forecast Using External Facility Data," Computational Intelligence, 2015 IEEE Symposium Series on, Cape Town, 2015, pp. 659-664.

[7]. M. Luo and X. Zhou, "Robustness of reverse triple I algorithms based on interval-valued fuzzy inference", International Journal of Approximate Reasoning, 66, 1626, November 2015

[8]. ISEP meteo website: http://meteo.isep.ipp.pt

[9]. J. Kim, N. Kasabov, HyFIS: adaptive neuro-fuzzy inference systems and their application to nonlinear dynamical systems, Neural Networks, Volume 12, Issue 9, November 1999, Pages 1301-1319, ISSBN 08936080

[10]. F. Gomide and W. Pedrycz, "Notions and Concepts of Fuzzy Sets", Fuzzy Systems Engineering: Toward Human-Centric Computing, 2007

[11]. L. X. Wang and J. M. Mendel, "Generating fuzzy rules by learning from examples," Intelligent Control, 1991., Proceedings of the 1991 IEEE International Symposium on, Arlington, VA, 1991, pp. 263-268.

[12]. K. Rudd, G. Di Muro and S. Ferrari, "A Constrained Backpropagation Approach for the Adaptive Solution of Partial Differential Equations," IEEE Trans. on Neural Networks and Learning Systems, vol. 25, no. 3, pp. 571,584, Mar. 2014 